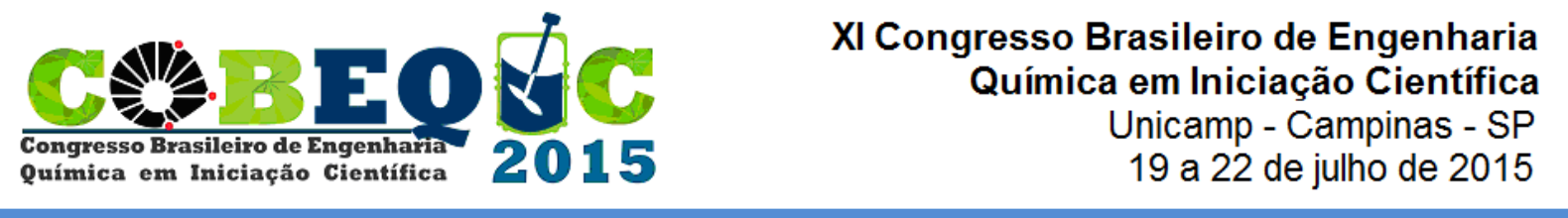

\title{
ADSORÇÃO DAS FRAÇÕES SOLÚVEIS DA GASOLINA EM ÁGUA
}

\author{
M. GUSTINELLI ${ }^{1}$, ROMBALDO. C. F. S ${ }^{1}$ \\ ${ }^{1}$ Universidade Metodista de Piracicaba, Faculdade de Engenharia, Arquitetura e Urbanismo, \\ Laboratório de Materiais Carbonosos ${ }^{1}$ \\ E-mail para contato: gustinelli@gmail.com
}

\begin{abstract}
RESUMO - Vazamento de gasolina resultando em contaminação de solo e água está se tornando cada vez mais frequente, em função disso é necessária a busca de uma técnica de descontaminação destas áreas. Uma das técnicas mais indicada para esse tipo de tratamento é a adsorção através de carvão ativado. Visando um estudo da capacidade de adsorção de alguns carvões ativados comerciais, nacional e importado, foram realizados ensaios de adsorção para a remoção dos poluentes oriundos da gasolina solúveis em água. Foram testados carvões ativados em pó em granular. Os carvões ativados em pó apresentaram maior capacidade de adsorção em relação aos carvões ativados granulares testados.
\end{abstract}

\section{INTRODUÇÃO}

Episódios de contaminação envolvendo hidrocarbonetos de gasolina são relatados com bastante frequência, principalmente em função dos também frequentes acidentes envolvendo transporte e estocagem de combustíveis (Farhadian et al., 2008). Dentro deste contexto, destaque deve ser dado aos hidrocarbonetos aromáticos como benzeno, tolueno, etilbenzeno e xilenos (BTEX), espécies monoaromáticas de reconhecida toxicidade e elevada solubilidade em água (Kermanshahi et al., 2007).

A gasolina comercializada no Brasil é misturada com álcool, e a partir de 16 de março de 2015 , o governo está autorizado por lei a elevar de $25 \%$ para $27,5 \%$ o percentual máximo de etanol na gasolina (Brasil, 2014). As interações entre o etanol e os BTEX podem causar um aumento da mobilidade e solubilidade, além de dificultar a biodegradação natural destes compostos.

Em função da elevada toxicidade dos hidrocarbonetos e da consequente diversidade de efeitos deletérios provocados nos ecossistemas contaminados, a procura por sistemas de remediação apresenta-se extremamente relevante (Tiburtius et al., 2009).

Uma técnica normalmente utilizada para a descontaminação destas águas é a extração por adsorção em carvão ativado (CA). A adsorção pode ser descrita como sendo o acúmulo de uma substância na interface de duas fases, como sólido (CA) e líquido (gasolina). O processo de adsorção, utilizando CA, é um método mundialmente utilizado, pois tem a capacidade de remover inúmeros tipos de poluentes da água (Tiburtius et al., 2004). 
O CA é um tipo de carbono caracterizado por se constituir de um material altamente poroso e por possuir uma área superficial específica (ASE) elevada. Estas características atribuem ao CA a propriedade de adsorver moléculas tanto da fase líquida como as moléculas da fase gasosa. São empregados para purificação de água e ar, em purificadores de sangue na medicina, além de muitas outras aplicações.

O benzeno, hidrocarboneto foco deste estudo de adsorção através de CA, é um líquido incolor, volátil e inflamável; largamente empregado na indústria química na síntese do etilbenzeno, fenol, ciclohexano e outros hidrocarbonetos aromáticos. O benzeno é adicionado na gasolina como aditivo para aumentar a octanagem (índice de resistência do combustível). No Brasil, o teor máximo de benzeno permitido em produtos acabados é $0,1 \%$, e a concentração máxima na gasolina automotiva é de até 1\% v/v (CETESB, 2012).

A inalação de altas concentrações de benzeno por curto tempo pode causar sonolência, enjoo, aceleração do ritmo cardíaco, cefaleia, tremor, confusão mental e inconsciência. A ingestão de alimentos e bebidas contaminados com altos teores de benzeno pode produzir vômito, irritação no estômago, enjoo, sonolência, convulsão, aceleração do batimento cardíaco e morte. A exposição por longo prazo pode resultar em depressão da medula óssea. A Agência Internacional de Pesquisa em Câncer (IARC) classifica o benzeno como cancerígeno humano (IARC, 1987).

\section{MATERIAIS E MÉTODOS}

Para o preparo da solução contaminada com as frações solúveis da gasolina em água, foi medida uma massa de $100 \mathrm{~g}$ de gasolina automotiva comum e um volume de $500 \mathrm{ml}$ água destilada. Os dois componentes foram misturados e agitados em um funil de separação de $1000 \mathrm{ml}$ durante 50 segundos e mantida em repouso por 5 minutos. Após este tempo, houve a separação de fases e a parte insolúvel em água foi retirada e reutilizada como gasolina, a fração solubilizada foi utilizada para os ensaios de adsorção.

Foram feitas leituras de absorbância da solução contaminada em um espectrofotômetro da marca Femto ${ }^{\circledR}$, modelo 800XI. Fazendo a varredura da solução $(190 \mathrm{~nm}$ a $400 \mathrm{~nm})$, o maior pico de absorbância encontrado foi em torno de $260 \mathrm{~nm}$ e dentre as frações de gasolina solubilizadas em água, esse pico indicou a presença do benzeno. Na literatura há relatos de $254 \mathrm{~nm}$ como sendo o comprimento de onda apropriado para as leituras de absorbância deste composto (Wibowo et al., 2007).

Para relacionar a concentração das amostras contaminadas com benzeno em água com as medidas de absorbância fornecidas pelo espectrofotômetro, foram feitas algumas diluições das amostras para a construção de uma curva de calibração.

Para a realização dos ensaios de adsorção, com CA granular, foi montado um sistema de fluxo contínuo, por meio de uma bomba peristáltica, utilizando uma mangueira de silicone, com diâmetro interno de $2 \mathrm{~mm}$. Em uma das extremidades da mangueira, conectou-se a uma cubeta de quartzo, na outra extremidade da mangueira foi conectado um sistema de retenção dos sólidos (para evitar que grãos de carvão sejam levados à cubeta) mergulhado na solução a ser analisada em um béquer, contendo tanto a solução, quanto o CA a ser testado. O modelo experimental esta ilustrado na Figura 1. 
Figura 1 - Sistema experimental: (I) béquer contendo solução contaminada; (II) sistema de retenção de sólidos; (III) agitador magnético; (IV) bomba peristáltica; (IV) espectrofotômetro

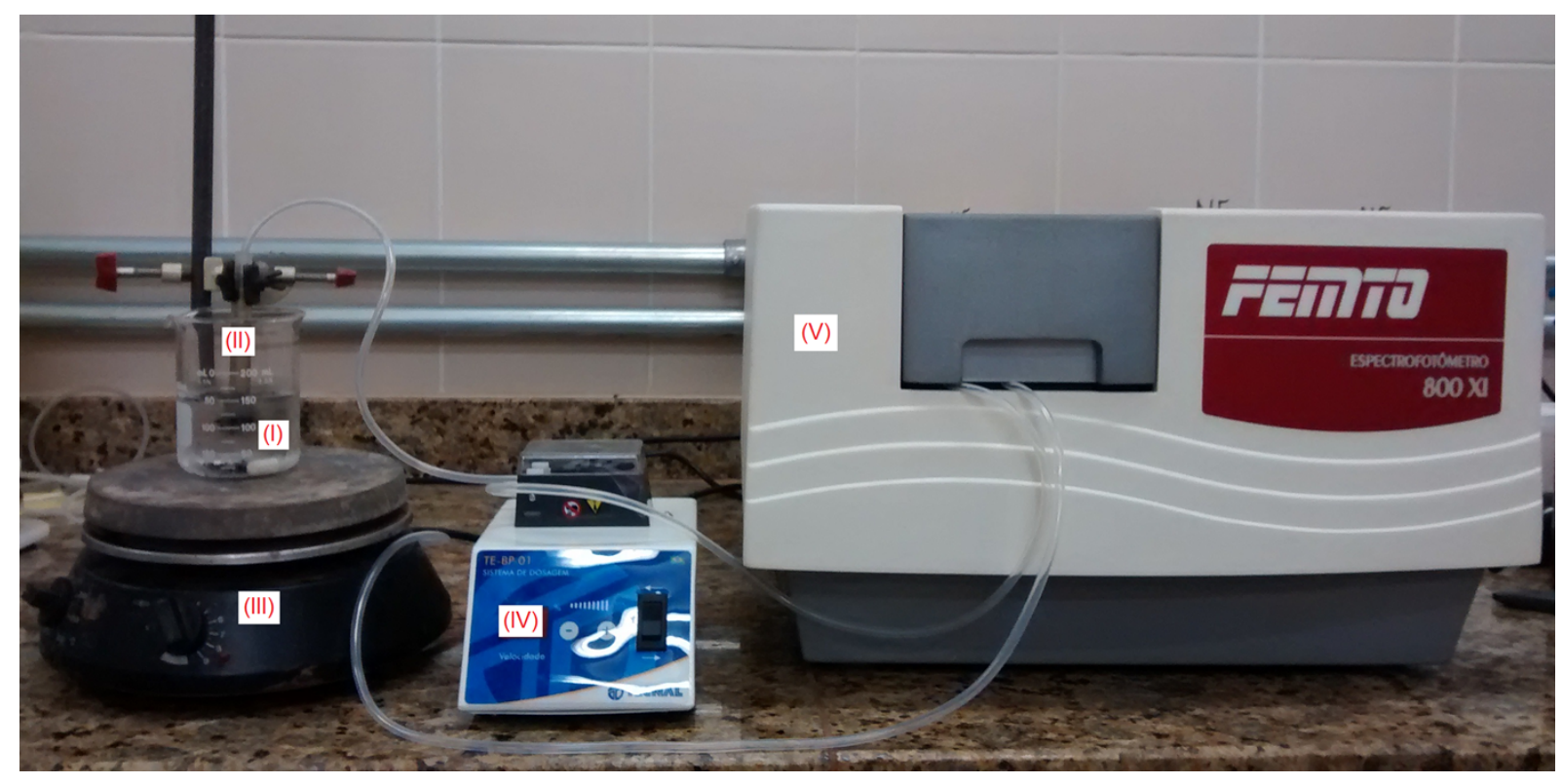

Para os ensaios de adsorção utilizando CA em pó, os materiais e a metodologia experimental utilizada foram quase os mesmos que os utilizados nos ensaios de adsorção com CA granular, sendo necessária uma mudança no sistema de retenção dos sólidos. Como o diâmetro do CA em pó é muito menor do que o granular foi utilizado um papel filtro comercial, para a retenção dos sólidos e consequentemente o contato entre o CA e a solução aquosa contaminada com as frações solubilizadas da gasolina.

Nos ensaios de adsorção, foram utilizados $200 \mathrm{~g}$ de solução contaminada e $0,1 \mathrm{~g}$ de CA a ser testado. Os ensaios duravam aproximadamente 10 horas. Foram testados carvões ativados comerciais em pó e granular, nacional (Carbomafra ${ }^{\circledR}$ ) e importado (Norit ${ }^{\circledR}$ ). A Tabela 1 apresenta a estrutura porosa dos CAs utilizados.

Tabela 1 - Características porosas dos CA comerciais testados

\begin{tabular}{|c|c|c|c|c|}
\hline CA & $\begin{array}{c}\text { Área superficial } \\
\text { específica } \\
\left(\mathrm{m}^{2} / \mathrm{g}\right)\end{array}$ & $\begin{array}{c}\text { Volume total de } \\
\text { poros } \\
\left(\mathrm{cm}^{3} / \mathrm{g}\right) \\
\end{array}$ & $\begin{array}{c}\text { Volume de } \\
\text { microporos } \\
\left(\mathrm{cm}^{3} / \mathrm{g}\right)\end{array}$ & $\begin{array}{c}\% \\
\text { microporo }\end{array}$ \\
\hline Carbomafra $^{\circledR}$ & 765 & 0,380 & 0,370 & 97,37 \\
\hline Norit $^{\circledR}$ & 959 & 0,545 & 0,506 & 92,84 \\
\hline
\end{tabular}

Como o benzeno é um hidrocarboneto muito volátil e como o sistema montado para os ensaios de adsorção é aberto, foi feito um ensaio sem CA, utilizando a mesma metodologia 


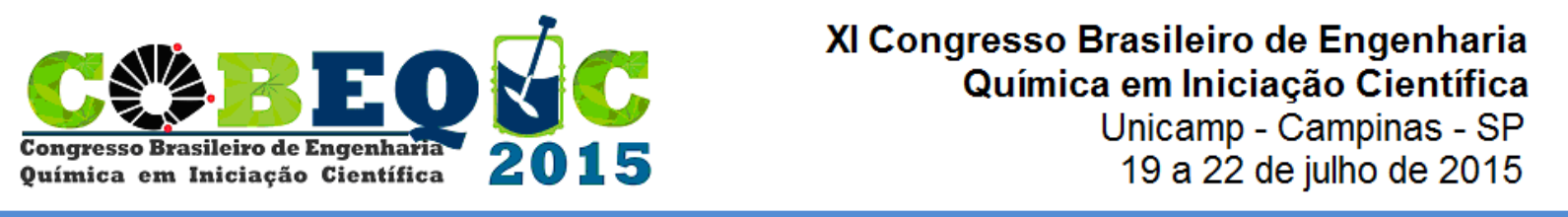

presente nos ensaios de CA em pó, a fim de verificar a quantidade de benzeno evaporada durante os ensaios de adsorção.

\section{RESULTADOS E DISCUSSÕES}

Após o ensaio sem a presença de CA, a fim de verificar a quantidade de benzeno, proporcional às frações solubilizadas na água, evaporada durante um ensaio de adsorção, foi feita uma relação entre a concentração final e a concentração inicial da solução (concentração relativa), como mostra a Figura 2, podendo confirmar que o benzeno é realmente um hidrocarboneto muito volátil, evaporando aproximadamente metade, ou seja, uma fração de 0,5 de sua concentração relativa durante a realização do ensaio sem a presença de CA.

Figura 2 - Ensaios de adsorção das frações solúveis da gasolina

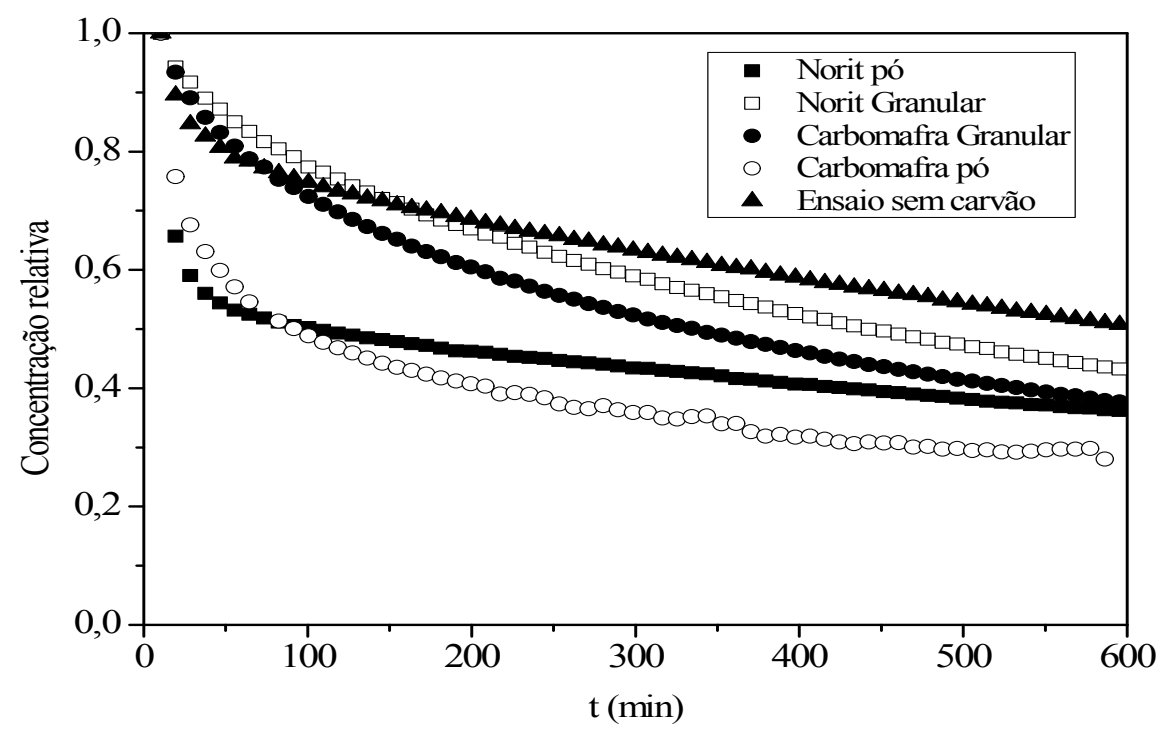

Analisando os resultados da Figura 2, pode-se notar uma maior e mais rápida capacidade de adsorção dos CA em pó, esse fato pode ser explicado pelo maior área de contato entre e o CA e a solução a ser adsorvida. Os CA em pó apresentaram um pico de adsorção nos primeiros 100 minutos de ensaio e após este tempo, nota-se que esta capacidade de adsorção cai e praticamente estabiliza-se, provavelmente pelos poros dos CAs estarem saturados. A queda de maneira acentuada e continua pode ser simplesmente a evaporação das frações solúveis da gasolina.

As proporções adsorvidas de contaminantes durante os ensaios em relação a concentração inicial, a quantidade em massa adsorvida, e a relação entre a massa dos contaminantes adsorvidas, já descontada a evaporação e a quantidade de CA utilizado no processo, estão representadas na Tabela 2. 
Tabela 2 - Rendimento dos CA comerciais testados

\begin{tabular}{c|c|c|c}
\hline CA testado & \% removida & $\begin{array}{c}\text { Quantidade } \\
\text { adsorvida }\end{array}$ & g contaminantes / g CA \\
\hline Carbomafra $^{\circledR}$ granular & 18 & $5,4 \mathrm{~g}$ & 54 \\
\hline Carbomafra $^{\circledR}$ pó & 25 & $7,5 \mathrm{~g}$ & 75 \\
\hline Norit $^{\circledR}$ granular $^{\text {Norit }}{ }^{\circledR}$ pó & 14 & $4,2 \mathrm{~g}$ & 42 \\
\hline
\end{tabular}

Uma comparação entre a granulometria dos CAs apresentados na Tabela 2 pode-se concluir que os CA em pó apresentaram um desempenho melhor que os CAs granulares. E, uma comparação entre a as marcas testadas, Carbomafra ${ }^{\circledR}$ e Norit ${ }^{\circledR}$, pode-se concluir o que o CA nacional, Carbomafra ${ }^{\circledR}$, foi superior ao CA importado, Norit ${ }^{\circledR}$, em todos os ensaios.

\section{CONCLUSÕES}

Os ensaios de adsorção realizados durante o projeto reafirmaram a volatilidade do benzeno, juntamente com os outros elementos solubilizados em água na preparação das soluções a serem analisadas, dificultando a determinação de resultados de adsorção, rendimento dos CAs testados, concentrações e massas finais dos contaminantes em água. A realização de um ensaio sem a presença de CA teve o objetivo de minimizar qualquer margem de erro.

Os resultados dos CAs comerciais testados expuseram a importância da granulometria do CA no processo de adsorção, os CAs no formato de pó obtiveram resultados melhores durante os ensaios, tanto na quantidade adsorvida, quanto no tempo de resposta, adsorvendo maiores quantidades em menores tempo, enquanto os CAs granulares apresentaram um comportamento de adsorção menos eficiente, este comportamento, próximo do da evaporação do benzeno e dos contaminantes solubilizados pela água.

Uma comparação entre os CAs testados e suas ASE, Tabela 1, pode-se notar que mesmo o CA da Norit ${ }^{\circledR}$ apresentando maior valores de ASE não foi CA que apresentou a maior capacidade de adsorção. Esse fato pode ser explicado pela presença dos grupos funcionais de superfície e pelo tamanho da molécula do adsorbato e o do poro do CA.

Mesmo após o término dos ensaios de adsorção, a solução de água contaminada analisada ficou distante de qualquer possibilidade de uso, tanto doméstico, quanto industrial. Ao término do ensaio com o CA granular da Carbomafra ${ }^{\circledR}$, após aproximadamente 10 horas de análise, a solução continha aproximadamente $16 \mathrm{~g} / \mathrm{L}$ de contaminantes, incluindo o benzeno, sendo que de acordo com a CETESB, a água potável deve conter no máximo 05 $\mu \mathrm{g} / \mathrm{L}$ de benzeno, sendo assim, esta solução teria de ser encaminhada para outros meios de purificação antes de qualquer uso. 


\section{REFERÊNCIAS}

BRASIL. Medida Provisória 647/2014, a lei 13.033/2014, publicada no Diário Oficial da União, 25/09/2014. Disponível em: http://www.planalto.gov.br/ccivil_03/Ato20112014/2014/Mpv/mpv647.htm. Acesso em: 20 de janeiro de 2015.

CETESB. Divisão de Toxicologia, Genotoxicidade e Microbiologia Ambiental. Benzeno. 2012

Disponível

em:

$<$ http://www.cetesb.sp.gov.br/userfiles/file/laboratorios/fit/benzeno.pdf $>$. Acesso em: 20 de agosto 2014.

FARHADIAN, M.; DUCHEZ, D.; VACHELARD, C.; LARROCHE, C.; Monoaromatics removal from polluted water through bioreactors. Water Res, v. 42, p. $1325-1341$. 2008 .

IARC. Overall evaluations of carcinogenicity: an updating of IARC Monographs volumes 1 to 42. IARC Monogr Eval Carcinog Risks Hum Suppl, 7: 1 - 440. 1987.

KERMANSHAHI, A.; KARAMANEV, D.; MARGARITIS, A. Kinetic modeling of the biodegradation of the aqueous p-xylene in the immobilized soil bioreactor. Biochemical Engineering Journal, v. 27, p. 204 - 211, 2006.

TIBURTIUS, E. R. L.; PERALTA-ZAMORA, P.; EMMEL, A. Degradação de benzeno, tolueno e xilenos em águas contaminadas por gasolina, utilizando-se processos fotoFenton. Quím. Nova, São Paulo, v. 32, n. 8, 2009.

TIBURTIUS, E. R. L.; PERALTA-ZAMORA, P.; LEAL, E. S. Contaminação de águas por BTXs e processos utilizados na remediação de sítios contaminados. Quím. Nova, São Paulo, v. 27, n. 3, 2004

WIBOWO, N.; SETYADHI, L.; WIBOWO, D.; SETIAWAN, J.; ISMADJI, S. Adsorption of benzene and toluene from aqueous solutions onto activated carbon and its acid and heat treated forms: Influence of surface chemistry on adsorption. Journal of Hazard Materials. v. 146. p. 237 -242. 2007. 